\title{
Efeito da Adição de Níveis Crescentes de Polpa Cítrica sobre a Qualidade Fermentativa e o Valor Nutritivo da Silagem de Capim-Elefante ${ }^{1}$
}

\author{
Paulo Henrique Mazza Rodrigues ${ }^{2}$, Laura Maria Oliveira Borgatti ${ }^{3}$, Rériton Weldert Gomes ${ }^{4}$, \\ Roberta Passini ${ }^{5}$, Paula Marques Meyer ${ }^{6}$
}

\begin{abstract}
RESUMO - Foram estudados os efeitos da adição de polpa cítrica sobre a qualidade fermentativa e o valor nutritivo da silagem de capim-elefante. O capim-elefante, apresentando 90 dias de crescimento, foi ensilado com níveis crescentes de polpa cítrica peletizada: $0 ; 2,5 ; 5 ; 7,5 ; 10 ; 12,5$ e 15\%, com base na matéria fresca. As silagens foram produzidas em 28 silos experimentais (quatro repetições/ tratamento), confeccionados a partir de baldes plásticos com válvulas do tipo Bunsen. A abertura dos silos ocorreu 106 dias após a ensilagem, quando foram determinados os teores dos ácidos orgânicos e a composição químico-bromatológica das silagens. Foi observado efeito linear crescente da adição de polpa cítrica sobre os teores de matéria seca, o mesmo ocorrendo para carboidratos solúveis e digestibilidade in vitro da matéria seca, mas com redução nos teores de nitrogênio amoniacal e fibra em detergente neutro. Para os teores de ácidos orgânicos (acético, lático e butírico) e etanol, observou-se comportamento quadrático para as curvas obtidas, com pontos de máxima para o ácido lático igual a 5,8\% e de mínima para os ácidos acético, butírico e o etanol, iguais a 7,8; 7,2; e -3,7\% de polpa, respectivamente. Não foram observados efeitos sobre os valores de $\mathrm{pH}$, assim como para os teores de lignina e de ácido propiônico. Inclusões de 4,7 a 7,6\% de polpa cítrica peletizada, com base na matéria fresca, são suficientes para melhorar a qualidade e o valor nutritivo da silagem de capim-elefante.
\end{abstract}

Palavras-chave: ácidos orgânicos, ensilagem, fermentação, Pennisetum purpureum, polpa de laranja

\section{Effect of Increasing Levels of Citrus Pulp on the Fermentation Quality and Nutritive Value of Elephantgrass Silage}

\begin{abstract}
The effects of increasing levels of citrus pulp on fermentation pattern and nutritive value of elephantgrass silage was evaluated. Elephantgrass harvested at 90 days was ensiled with increasing levels of dried citrus pulp: 0, 2.5, 5, 7.5, 10, 12.5 and 15\% (fresh matter basis). Silages were produced in 28 plastic experimental silos ( 4 replicates/treatment) bearing Bunsen valves. Silos were opened 106 days after ensiling, when samples were taken for the analysis of silages organic acids and chemical components. Silage dry matter concentration increased linearly with level of citrus pulp. The same effect was observed for the water soluble carbohydrate concentration and the "in vitro" dry matter digestibility. However, ammoniacal nitrogen and neutral detergent fiber levels decreased linearly with citrus pulp addition. The response was quadratic for organic acids (acetic, lactic and butyric) and ethanol. The maximum point for lactic acid was observed with $5.8 \%$ and the minimal point for acetic, butyric and ethanol was observed with $7.8 \%, 7.2 \%$ and $-3.7 \%$ of citrus pulp inclusion, respectively. Citrus pulp did influence neither $\mathrm{pH}$, nor lignin and propionic acid levels. Inclusions of 4.7 to $7.6 \%$ of citrus pulp (fresh matter basis) are enough to improve the elephantgrass silage quality.
\end{abstract}

Key Words: organic acids, ensiling, fermentation, Pennisetum purpureum, orange pulp

\section{Introdução}

A ensilagem do capim-elefante (Pennisetum purpureum, Schum), como forma de aproveitamento do excedente de forragem produzido no período nas águas, é recomendada há pelo menos vinte anos, por permitir sua conservação para suplementação dos animais na estação seca. Com base nas informações em que se associam rendimento forrageiro e valor nutritivo, alturas de 160 a $185 \mathrm{~cm}$ e/ou idades de 56 a 80 dias têm sido sugeridas como ideais para o corte do capim-elefante para ensilagem (Vilela, 1990). Contudo, neste estádio de desenvolvimento, o excesso de umidade ( $80 \%$ ou mais) implica em riscos à ação de microrganismos indesejáveis (Wilkinson, 1983). A menor pressão osmótica neste momento favorece o desenvolvimento das bactérias do gênero Clostridium e de outras que desdobram açúcares, ácido lático,

\footnotetext{
${ }_{1}^{1}$ Financiado pela Fundação de Amparo à Pesquisa do Estado de São Paulo (FAPESP).

2 Prof. Depto. de Nutrição e Produção Animal - FMVZ/USP, Campus de Pirassununga-SP, CEP: 13.630-000. Bolsista de Produtividade em Pesquisa do CNPq. E.mail: pmazza@usp.br

3 Doutoranda do Laboratório de Nutrição Animal - CENA/USP, Piracicaba-SP.

4 Bolsista de Iniciação Científica (CNPq).

5 Pós-doutoranda do Depto. de Nutrição e Produção Animal - FMVZ/USP, Campus de Pirassununga-SP.

6 Pesquisadora do Instituto Brasileiro de Geografia e Estatística-IBGE.
} 
proteínas e aminoácido em ácidos acético e butírico, nitrogênio amoniacal $\left(\mathrm{N}-\mathrm{NH}_{3}\right)$ e aminas, substâncias que afetam o consumo da silagem (Whittemburry etal., 1967).

Segundo Silveira (1987), os capins tropicais, além de conter elevado teor de umidade, normalmente, são pobres em carboidratos solúveis e apresentam alto poder tampão, características que reduzem o sucesso da ensilagem. Sabe-se que o teor de carboidratos solúveis das plantas forrageiras durante a ensilagem é fundamental para que o processo fermentativo se desenvolva de maneira eficiente (McDonald, 1981). Os carboidratos solúveis são os substratos prontamente disponíveis para o desenvolvimento das bactérias desejáveis, sobretudo as láticas, viabilizando a adequada produção de ácido lático e a rápida redução do potencial hidrogeniônico $(\mathrm{pH})$, condição necessária para a inibição da atividade proteolítica das enzimas vegetais e do desenvolvimento das bactérias indesejáveis (Muck, 1988).

Evidências experimentais têm sugerido que a inclusão de uma fonte de carboidratos solúveis ao capimelefante durante a ensilagem pode melhorar consideravelmente a qualidade final das silagens. Diversas pesquisas têm sido realizadas com o propósito de avaliar alguns aditivos e outras alternativas que possam beneficiar o processo fermentativo de silagens de capimelefante, como a adição de fontes de carboidratos, de materiais com elevados teores de matéria seca (Veiga \& Campos, 1975), de inoculantes enzimo-bacterianos (Henrique \& Bose, 1992) e de substâncias nitrogenadas (Singh \& Pandita, 1984) além da execução do prémurchamento do capim (Tosi, 1973).

Entre os aditivos comumente utilizados para a produção de silagens de capim elefante, a polpa cítrica tem proporcionado bons resultados, em razão de seu alto teor de matéria seca e de carboidratos solúveis e de sua capacidade de absorver água, tornando-a capaz de contribuir para fermentações desejáveis que ocorrem no interior da massa ensilada (Faria et al., 1972).

Este trabalho foi conduzido com o objetivo de avaliar a qualidade fermentativa e ao valor nutritivo da silagem de capim-elefante a inclusão de níveis crescentes de polpa cítrica na ensilagem.

\section{Material e Métodos}

O trabalho foi conduzido nas dependências do Departamento de Nutrição e Produção Animal da Faculdade de Medicina Veterinária e Zootecnia da Universidade de São Paulo (Campus de Pirassununga-SP).
O capim-elefante (Pennisetum purpureum, cultivar Napier) foi cortado aos 90 dias de crescimento, picado em fragmentos médios de $2,5 \mathrm{~cm}$ e, após homogeneização, foi colocado em silos experimentais. Foram utilizados 28 baldes plásticos com $252 \mathrm{~mm}$ de altura e $245 \mathrm{~mm}$ de diâmetro e tampa superior com válvula tipo "bunsen" para o livre escape dos gases. O delineamento adotado foi o inteiramente casualizado, com sete tratamentos (sete níveis de inclusão de polpa cítrica) e quatro repetições. Os tratamentos consistiram de sete grupos $(0 ; 2,5 ; 5 ; 7,5 ; 10 ; 12,5$ e $15 \%)$ de polpa cítrica peletizada, adicionada com base na matéria fresca da polpa e do capim. Para enchimento dos silos, considerou-se a densidade de $500 \mathrm{~kg}$ de forragem por metro cúbico.

Antes da abertura, os silos foram pesados, para posterior determinação das perdas de matéria seca (MS). Uma vez abertos, as massas retiradas de cada silo foram homogeneizadas, separando-se uma parcela, para determinação dos teores de matéria seca, em estufa de ventilação forçada, e de proteína bruta (PB), segundo AOAC (1975). Os componentes da parede celular, como fibra em detergente neutro (FDN) e lignina, estimado pelo método do permanganato, foram avaliados segundo Van Soest (1967), os carboidratos solúveis, conforme Johnson et al. (1966), o nitrogênio insolúvel em detergente ácido (NIDA), segundo Van Soest \& Robertson (1985), o poder tampão, segundo Tosi (1973) e a digestibilidade in vitro da matéria seca (DIVMS), segundo Tilley \& Terry (1963). Para a análise da FDN, foi omitido o sulfito de sódio e adicionada a $\alpha$ amilase. Outra fração de silagem foi colocada em prensa manual, para extração dos sucos e imediata determinação do $\mathrm{pH}$ (medição em potenciômetro). Parte do suco foi fixada $(0,2 \mathrm{~mL}$ de ácido fórmico para cada 1,0 $\mathrm{mL}$ de suco de silagem) e congelada para posterior determinação dos ácidos orgânicos, por cromatografia gasosa (Erwin et al., 1961). Outra parte do suco foi ainda fixada $(1,0 \mathrm{~mL}$ de ácido sulfúrico; $1 \mathrm{~N}$ para cada 2,0 $\mathrm{mL}$ de suco de silagem) e congelada, para posterior determinação do nitrogênio amoniacal por espectofotometria (Foldager, 1977). As perdas por fermentação foram calculadas pela diferença entre os pesos das massas obtidos ao enchimento e à abertura dos silos, multiplicados pelos respectivos teores de matéria seca. Finalmente, as perdas foram transformadas em porcentagem da massa inicial. 
Os dados foram submetidos à análise de regressão polinomial, pelo procedimento GLM do pacote estatístico SAS (SAS, 1985), decompondo-se os efeitos em lineares e quadráticos.

\section{Resultados e Discussão}

Os dados da composição bromatológica do capimelefante e da polpa cítrica utilizada encontram-se na Tabela 1. Os teores das diversas frações de nutrientes para o capim-elefante foram compatíveis aos do capim cortado aos 90 dias de idade e os dados de polpa cítrica, semelhantes aos relatados na literatura (Carvalho, 1996).

À medida que se elevou o nível de inclusão da polpa cítrica na massa ensilada, o teor de matéria seca das silagens aumentou linearmente $(\mathrm{P}<0,05)$ (Tabela 2$)$, em razão de a polpa conter elevado teor de matéria seca $(86,5 \%)$. Resultado semelhante foi obtido por Evangelista et al. (2001), ao adicionarem níveis crescentes de polpa cítrica $(5,10$ e $15 \%)$ em silagem de Coast-cross. Faria et al. (1972) observaram que a inclusão de até $20 \%$ de polpa cítrica seca na silagem de capim-elefante possibilitou o aumento do teor de matéria seca da silagem para $32 \%$, resultando em silagem de boa qualidade. Entretanto, Netto et al. (2002) não verificaram aumento significativo do teor de MS ao adicionarem $10 \%$ de polpa cítrica peletizada na silagem de capim-elefante. Os valores de matéria seca obtidos para a silagem neste experimento estão abaixo dos níveis de 30 a 40\%, citados por Silveira (1987) como necessários para garantir produção de silagem de boa qualidade. Observou-se também, neste estudo, que, a partir da inclusão de $10 \%$ de polpa cítrica, a porcentagem de matéria seca da silagem foi elevada a níveis superiores a 26\%, o que está acima do limite de $25 \%$, recomendado por Faria (1986) como mínimo necessário para a ensilagem do capim-elefante. Entretanto, deve-se considerar a grande capacidade de absorção de água da polpa cítrica, decorrente do seu elevado teor de pectina. Mesmo apresentando alta umidade, é possível que a pectina indisponibilize a água para que ocorra o crescimento de bactérias indesejáveis.

A adição de polpa cítrica, com seu elevado teor de carboidratos solúveis $(25,96 \%$ da MS), propiciou aumento linear $(\mathrm{P}<0,05)$ da concentração destes na massa ensilada. Silveira (1987) afirma que o conteúdo de carboidratos solúveis na planta é um fator importante, uma vez que estes são os principais substratos das bactérias formadoras de ácido lático.

Houve efeito quadrático $(\mathrm{P}<0,05)$ para os teores de proteína com a adição de polpa. Os valores absolutos obtidos para este parâmetro foram considerados baixos, embora valores superiores a $4,9 \%$ de polpa sejam compatíveis com o nível mínimo de 7\% de PB, citado por Coelho da Silva \& Leão (1979) como necessário para o bom funcionamento ruminal. Este resultado difere do encontrado por Pedreira et al. (2001), que observaram declínio no teor de proteína bruta com a adição de polpa cítrica. De acordo com Bhattacharya \& Harb (1973), o teor de proteína da polpa cítrica é baixo e sua constituição aminoacídica, de reduzido valor. O ponto de máxima concentração de proteína bruta, estimado pela derivação da equação quadrática, foi encontrado com a adição de 7,61\% de polpa cítrica neste experimento.

Foi observado comportamento quadrático $(P<0,05)$ para os teores de NIDA à medida que foi aumentada a inclusão de polpa cítrica. Até o nível de 4,7\% de

Tabela 1 - Composição bromatológica da matéria original do capim-elefante e da polpa cítrica, expressos com base na matéria seca ${ }^{1}$

Table 1 - Chemical composition of elephantgrass and citrus pulp original matter (in dry matter basis) ${ }^{1}$

\begin{tabular}{|c|c|c|c|c|c|c|c|c|}
\hline & $\begin{array}{l}\text { MS } \\
D M\end{array}$ & $\begin{array}{l}\mathrm{PB} \\
C P\end{array}$ & $\begin{array}{l}\text { NIDA } \\
A D I N\end{array}$ & $\begin{array}{l}\text { FDN } \\
N D F\end{array}$ & $\begin{array}{l}\mathrm{LIG} \\
L I G \\
\end{array}$ & $\begin{array}{c}\text { CHOs } \\
W S C \\
\end{array}$ & $\begin{array}{l}\text { DIVMS } \\
I V D M D\end{array}$ & $\begin{array}{l}\mathrm{PT} \\
B C \\
\end{array}$ \\
\hline $\begin{array}{l}\text { Capim-elefante } \\
\text { Elephantgrass }\end{array}$ & 20,71 & 7,24 & 27,62 & 75,41 & 15,91 & 5,00 & 49,96 & 15,98 \\
\hline $\begin{array}{l}\text { Polpa cítrica } \\
\text { Citrus pulp }\end{array}$ & 86,5 & 7,35 & 27,11 & 25,75 & 5,0 & 25,96 & - & - \\
\hline
\end{tabular}

${ }^{1}$ MS: matéria seca total (\%); PB: proteína bruta (\% MS); NIDA: nitrogênio insolúvel em detergente ácido ( $\%$ do N total); FDN: fibra em detergente neutro (\% MS); lignina (\% MS); CHOs: carboidratos solúveis (\% MS); DIVMS: digestibilidade in vitro da matéria seca (\% MS) e PT: poder tampão (meq./100 g MS de forragem).

${ }^{1}$ DM: dry matter (\%); CP: crude protein (DM \%); ADIN: acid detergent insoluble nitrogen (\% of total N); NDF: neutral detergent fiber (DM $\%)$; LIG: lignin (DM \%); WSC: water-soluble carbohydrate (DM \%); IVDMD: in vitro dry matter digestibility (DM \%); BC: buffering capacity (meq./100 g of DM) 


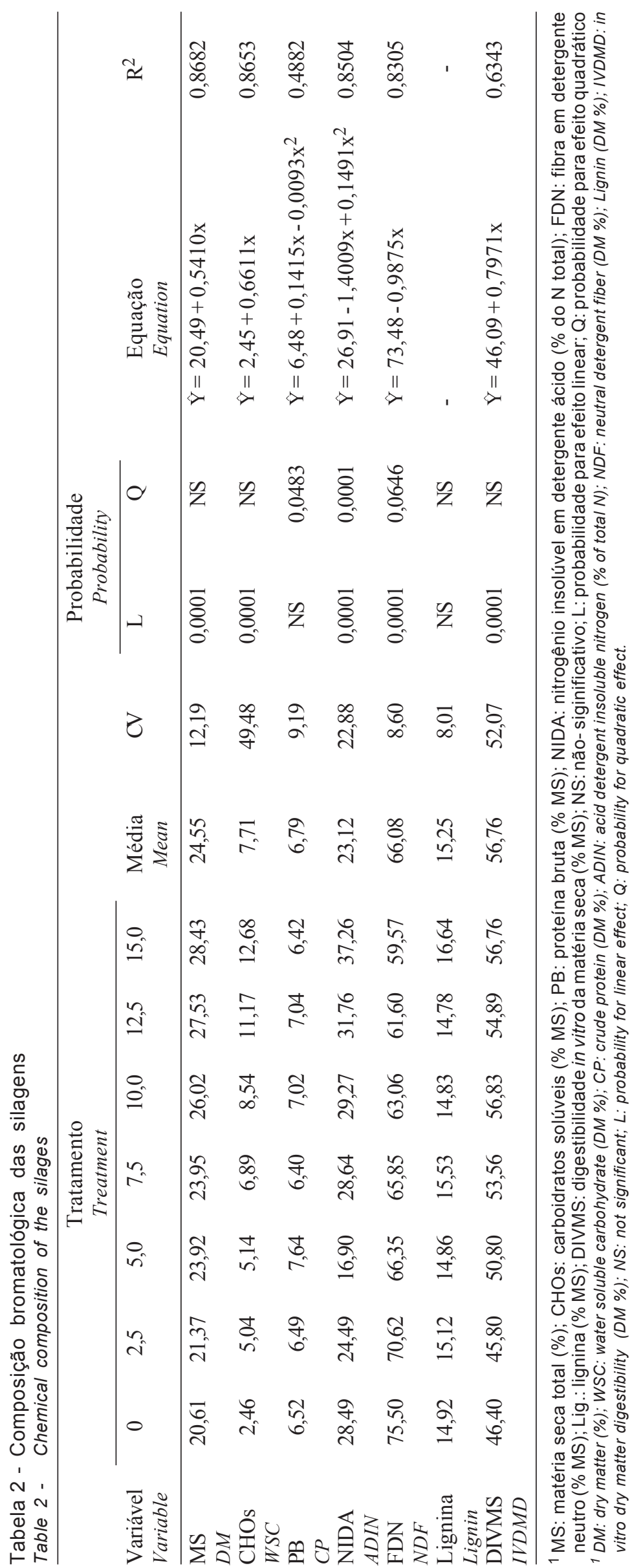


inclusão, foi observada queda no teor de NIDA. Porém, acima deste nível, os valores elevaram, sugerindo que o acréscimo de polpa cítrica nas silagens promove aumento de frações indigeríveis, como o NIDA. Este resultado é, provavelmente, decorrente do processo de aquecimento da silagem, como proposto por Mir et al. (1995), fenômeno que deve ter ocorrido nas silagens com elevados níveis de polpa, possivelmente em função da elevação do teor de matéria seca ou, então, da baixa disponibilidade de água livre. O aquecimento da forragem, processo conhecido como reação de Mayllard ou como caramelização, promove complexação do nitrogênio à fibra, especialmente a hemicelulose, levando à indisponibilização do nitrogênio.

Os teores de FDN das silagens foram reduzidos linearmente $(\mathrm{P}<0,05)$ à medida que se elevou a adição de polpa cítrica, o que é justificado pelo baixo teor de FDN deste aditivo $(25,75 \%$ da $\mathrm{MS})$, em comparação ao teor observado no capim-elefante $(75,41 \%)$. Os teores de FDN registrados neste experimento estão de acordo com os observados por Pedreira et al. (2001). Não houve efeito da inclusão da polpa cítrica sobre os teores de lignina.

A digestibilidade in vitro da MS da silagem aumentou linearmente $(\mathrm{P}<0,05)$ com a inclusão de polpa cítrica, provavelmente em virtude dos altos coeficientes de digestibilidade da MS deste subproduto, conforme observaram Schultz et al. (1993). Wainman \& Dewey (1988) também reportaram alta digestibilidade in vitro de $\mathrm{MO}$ e FDN em silagens com polpa cítrica.

Os dados de fermentação das silagens submetidas aos diferentes tratamentos encontram-se na Tabela 3. A concentração de etanol foi afetada significativamente pela inclusão de polpa cítrica. Esta resposta foi do tipo quadrática $(\mathrm{P}<0,05)$ e a menor concentração de etanol, encontrada pela derivação da equação, foi obtida quando a adição de polpa cítrica foi negativa $(-3,72 \%)$. O aumento do etanol em função dos níveis de polpa cítrica é indicativo de rápida acidificação da silagem. Este resultado é compatível com o postulado por Chamberlain (1987), em que a rápida acidificação poderia favorecer o desenvolvimento de leveduras não sensíveis ao baixo $\mathrm{pH}$ e promover a fermentação de açúcares residuais a etanol.

Também a resposta dos níveis de polpa cítrica sobre o teor de ácido acético foi do tipo quadrática $(\mathrm{P}<0,05)$, com a menor concentração para o ácido acético obtida com 7,8\% de inclusão de polpa cítrica. Todos os valores de ácido acético verificados com a adição de polpa cítrica, mesmo nos tratamentos com menor inclusão (2,5\% de polpa), estão abaixo do nível crítico de $0,8 \%$ deste ácido. Níveis de ácido acético superiores a este indicam alterações indesejáveis ocorridas durante o processo de ensilagem (Mahanna, 1997).

A menor produção de ácido butírico foi observada com o nível de $7,2 \%$ de inclusão de polpa cítrica, embora 5,0\% deste subproduto já possibilitasse a redução na concentração deste ácido. A produção de ácido butírico foi baixa em todos os tratamentos, com valores obtidos próximos de zero, o que, segundo Silveira (1987), é indicativo de que as transformações desejáveis ocorreram dentro da massa ensilada.

A produção máxima de ácido lático foi registrada com 5,8\% de inclusão de polpa cítrica. Entretanto, todos os tratamentos apresentaram valores superiores a 3,0\% de ácido lático, o que caracteriza uma silagem de boa qualidade (Vilela, 1990). O ácido lático é um dos principais responsáveis pela rápida queda e manutenção do $\mathrm{pH}$, por apresentar maior constante de dissociação, com a conseqüente estabilização do meio. Vilela (1998) afirma que, em silagens de boa qualidade, o ácido lático aparece em altas porcentagens, enquanto o ácido butírico deve ser baixo ou nulo. É importante destacar que a inclusão de níveis superiores a 5,8\% de polpa cítrica promoveu redução das concentrações de ácido lático das silagens, provavelmente pelo fato de ser necessário menor quantidade de ácido lático para bloquear a continuidade do processo fermentativo, nas situações em que a osmolaridade do meio for maior.

A adição de polpa cítrica à silagem não alterou a concentração de ácido propiônico nem o pH. Os valores de $\mathrm{pH}$ encontrados estão dentro da faixa considerada ótima para fermentação adequada que, segundo McDonald (1981), se encontra entre 3,8 e 4,2. O mesmo foi demonstrado por Evangelista et al. (2000), que, ao adicionarem $4 \%$ de polpa cítrica em silagem da gramínea estrela roxa (Cynodon nlemfuensis Vanderyst), não observaram alteração do $\mathrm{pH}$. Segundo Van Soest (1994), em silagens convencionalmente conservadas, o pH alto é indicativo de maior produção dos ácidos butírico e acético, que são característicos dos processos de fermentações indesejáveis. Entretanto, o pH isoladamente não pode ser considerado como critério seguro para avaliação da fermentação, pois seu efeito inibitório sobre as bactérias depende da velocidade do abaixamento e da umidade do meio (Woolford, 1984). 


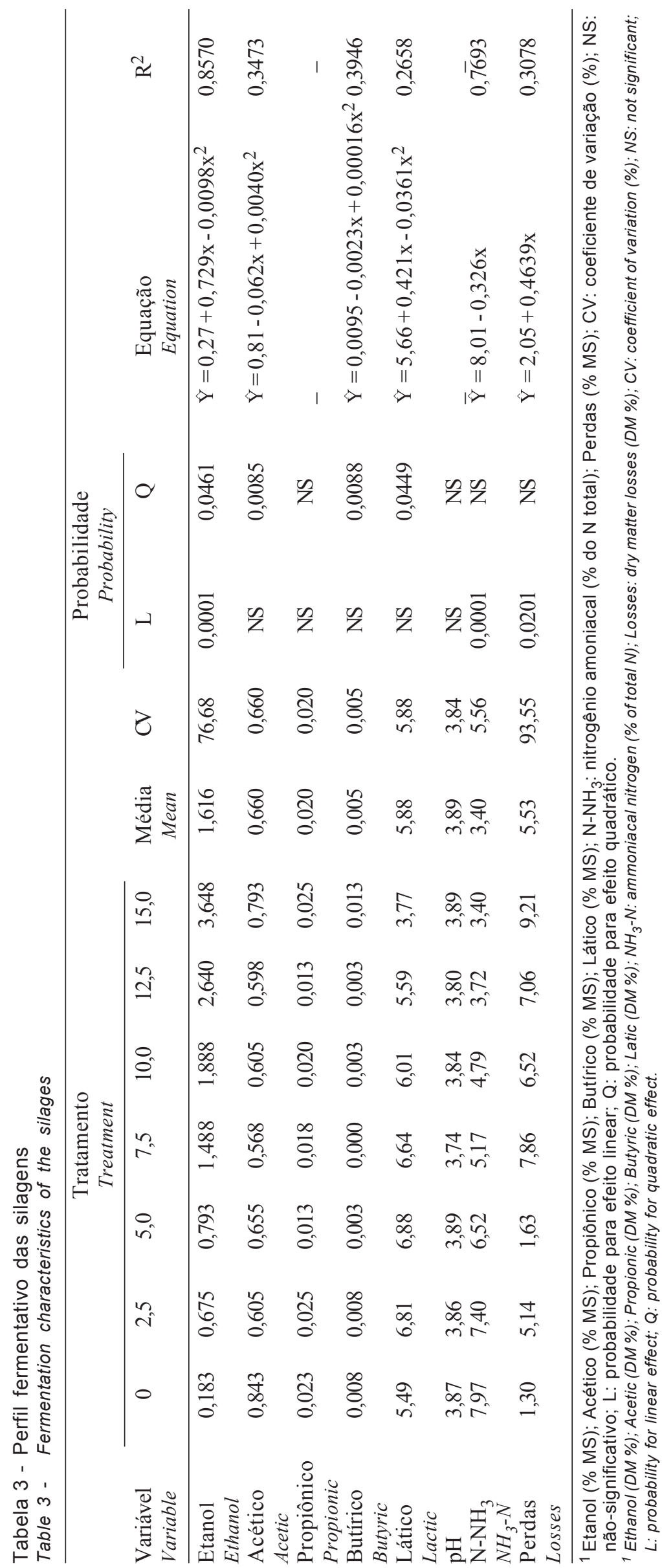


A adição de polpa cítrica diminuiu linearmente $(\mathrm{P}<0,05)$ os valores de nitrogênio amoniacal, provavelmente em virtude da baixa proteólise resultante da atividade das enzimas da planta, uma vez que grande parte das enzimas vegetais que desintegram proteína da forragem no interior do silo é ativa somente em $\mathrm{pH}$ acima de 5,0. Silveira (1987), ao fazer uma síntese de diversos autores, afirma que silagens com valores de nitrogênio amoniacal de até $8 \%$ do $\mathrm{N}$ total são consideradas de boa qualidade.

As perdas de matéria seca foram maiores $(\mathrm{P}<0,05)$ à medida que se aumentou o nível de inclusão de polpa cítrica na silagem. $\mathrm{O}$ aumento da disponibilidade de carboidratos solúveis para os microrganismos, com a inclusão da polpa cítrica, foi possivelmente o fator que proporcionou as maiores perdas. O aumento da produção de etanol, observado com a inclusão de polpa no presente experimento, poderia ser responsável por maiores perdas de carbono, na forma de $\mathrm{CO}_{2}$. Embora as produções de ácidos acético e butírico tivessem sido diminuídas com níveis intermediários de inclusão de polpa cítrica, a magnitude de variação na concentração dos ácidos acético $(0,568-0,843 \%$ da MS) e butírico $(0,000-0,013 \%$ da MS) foi muito menor que a do etanol (0,183-3,648\% da MS). Adicionalmente, maiores concentrações de carboidratos solúveis poderiam ocasionar maior produção de produtos da fermentação voláteis (ácidos orgânicos, etanol e outros), que podem ser perdidos principalmente durante a secagem da silagem na estufa.

\section{Conclusões}

Inclusões de 4,7 a 7,6\% de polpa cítrica peletizada, com base na matéria fresca do capim, são suficientes para melhorar a qualidade de fermentação e o valor nutritivo da silagem de capim-elefante. Níveis superiores podem comprometer a fermentação ou o valor nutritivo.

\section{Agradecimento}

Aos funcionários Everson Lázaro e Gilmar Botteon, pelo cuidado com a cultura, e aos técnicos Ari de Castro, Gilson de Godoy e Simi Robassini, pela ajuda com as análises laboratoriais.

\section{Literatura Citada}

ASSOCIATION OF ANALYTICAL CHEMISTIS - AOAC Official methods of analysis. 12.ed. Washington, D.C.: 1975. 1094p.

BHATTACHRYA, A.N.; HARB. M. Dried citrus pulp as a grain replacement for awase lambs. Journal of Animal Science, v.36, n.4, p.1175-1180, 1973.

CARVALHO, M.P. Aditivos para silagem de plantas de clima tropical. In: SIMPÓSIO SOBRE NUTRIÇÃO DE BOVINOS, 6., 1996, Piracicaba. Anais... Piracicaba: Fundação de Estudos Agrários "Luis de Queiroz" 1996. p.171-214.

CHAMBERLAIN, D.G. The silage fermentation in relation to the utilization of nutrients in the rumen. Process Biochemistry, v.4, n.1, p.60-63, 1987

ERWIN, E.S.; MARCO, G.J.; EMERY, E.M. Volatile fatty acid analyses of blood and rumen fluid by gas chromatography. Journal of Dairy Science, v.44, n.9, p.1768-1771, 1961.

EVANGELISTA, A.R.; LIMA, J.A.; BERNARDES, T.F. Avaliação de algumas características da silagem de gramínea Estrela Roxa. Revista Brasileira de Zootecnia, v.29, n.4, p.941-946, 2000

EVANGELISTA, A.R.; LIMA, J.A.; SIQUEIRA, G.R. et al. Aditivos na ensilagem de Coast Cross (Cynodon dactylon (L.) Pers) 1. Farelo de trigo e polpa cítrica. In: REUNIÃO ANUAL DA SOCIEDADE BRASILEIRA DE ZOOTECNIA, 38. 2001, Piracicaba. Anais... Piracicaba: Sociedade Brasileira de Zootecnia, 2001. CD-ROM. (Forragicultura. FOR-0032).

FARIA, V.P. Técnicas de produção de silagem. In: CONGRESSO BRASILEIRO DE PASTAGENS, 1., 1986, Piracicaba. Anais... Piracicaba: Fundação de Estudos Agrários Luiz de Queiroz, 1986.p.119-144.

FARIA, V.P.; TOSI, H.; GODOY, C.R.M. Polpa de laranja seca e fresca como aditivos para ensilagem de capim-elefante Napier. Solo, v.64, n.1, p.41-46, 1972.

FOLDAGER, J. Protein requeriment and non protein nitrogen for high producing cow in early lactation. East Lansing: Michigan State University, 1977. 167p. Thesis (Ph.D. in Animal Science) - Michigan State University, 1977.

HENRIQUE, W.; BOSE, M.L.V. Efeito de aditivos enzimobacterianos sobre a qualidade da silagem de capim-elefante (Pennisetum purpureum, Schum). Revista Brasileira de Zootecnia, v.21, n.3, p.429-437, 1992.

JOHNSON, R.R.; BALWANI, T.L.; JOHNSON, L.J. et al. Corn plant maturity. II Effect on in vitro cellulose digestibility and soluble carbohydrate content. Journal of Animal Science, v.25, n.3, p.617-623, 1966.

MAHANNA, B. Troubleshooting silage problems. Acessado em: 20 de outubro de 1997. Disponível em: http://www.pioneer.com/xweb.

McDONALD, P. The biochemistry of silage. Nova York John Wiley \& Sons, 1981. 226p.

MIR, Z.; JAN, E.Z.; ROBERTSON, J.A. et al. Effects of microbial inoculant and moisture content on preservation and quality of round baled alfalfa. Canadian Journal of Animal Science, v.75, n.1, p.15-23, 1995.

MUCK, R.E. Factors influencing silage quality and their implications for management. Journal of Dairy Science, v.71, n.11, p.2992-3002, 1988. 
NETTO, A.R.; PAIVA, F.A.; HERLING, V.R. et al. Efeito de aditivos e pré-emurchecimento na composição química de silagens de capim-elefante (Pennisetum purpureum SCHUM CV. NAPIER). In: REUNIÃO ANUAL DA SOCIEDADE BRASILEIRA DE ZOOTECNIA, 39., 2002, Recife. Anais... Recife: SBZ, 2002. CD-ROM. (Forragicultura. FOR-245).

PEDREIRA, M.S.; MOREIRA, A.L; REIS, R.A. et al. Características químicas e fermentativas do Tifton 85 (Cynodon ssp.) ensilado com diferentes conteúdos de matéria seca e níveis de polpa cítrica. In: REUNIÃO ANUAL DA SOCIEDADE BRASILEIRA DE ZOOTECNIA, 38., 2001, Piracicaba. Anais... Piracicaba: Sociedade Brasileira de Zootecnia, 2001. CD-ROM. (Forragicultura. FOR-0192).

STATISTICAL ANALYSES SYTEM - SAS. SAS/STAT@ user's guide: statistics. Release 6. 4.ed. Cary: 1985.

SCHULTZ, T.A.; COLLAR, C.A.; BATH, D.I. et al. Rumen digestion of various dairy feedstuffs compared in tests. California Agriculture, v.3, n.1, p.29-38, 1993.

SILVA, J.C.; LEÃO, M.I. Fundamentos de nutrição dos ruminantes. Piracicaba: Livroceres, 1979. p.190-236.

SILVEIRA, A.C. Produção e utilização de silagens. In: SEMANA DE ZOOTECNIA, 12., 1987, Pirassununga. Anais... Pirassununga: Fundação Cargill, 1987. p.119-134.

SINGH, A.P.; PANDITA, N.N. Effect of urea and molasses on fermentation of Napier silage. Indian Journal Animal Science, v.54, n.1, p.112-1145, 1984.

TILLEY, J.M.A.; TERRY, R.A. A two-stage technique for the "in vitro" digestion of forage crops. The Journal of the British Grassland Society, v.18, n.2, p.104-111, 1963.

TOSI, H. Conservação de forragem como consequência do manejo. In: SIMPÓSIO SOBRE MANEJO DE PASTAGENS, 1., Piracicaba. Anais... Piracicaba: Fundação de Estudos Agrários Luiz de Queiroz, 1973. p.117-140.

Van SOEST, P.J. Development of a comprehensive system for analysis and its application to forage. Journal of Animal Science, v.26, n.1, p.119-128, 1967.
Van SOEST, P.J. Nutritional ecology of the ruminant. Corvallis: O\&B Books, 1994. 476p.

Van SOEST, P.J.; ROBERTSON, J.B. Analysis of forages and fibrous food. 1.ed. Ithaca: Cornell University, 1985. 202p.

VEIGA, J.B.; CAMPOS, J. Emprego de melaço, pirossulfito de sódio, uréia e cama de galinheiro no preparo de silagem de capim elefante. Experimentiae, v.19, n.1, p.1-16, 1975.

VILELA, D. Utilização do capim elefante na forma de forragem conservada. In: SIMPÓSIO SOBRE CAPIM ELEFANTE, 1990, Coronel Pacheco. Anais... Juiz de Fora: Embrapa Gado de Leite, 1990. p.89-131.

VILELA, D. Aditivos para silagem de plantas de clima tropical. In: REUNIÃO ANUAL DA SOCIEDADE BRASILEIRA DE ZOOTECNIA, 35., 1998, Botucatu. Anais... Botucatu: Sociedade Brasileira de Zootecnia, 1998. p.73-103.

WAINMAN, F.W.; DEWEY, J.S. Feedingstuffs evaluation unit. London: Rowett Research Institute, 1988. 123p.

WHITTENBURRY, R.; McDONALD, P.; BRYAN JONES, D.G. A short review of some biochemical and microbiological aspects of ensilage. Journal of Science and Food Agriculture, v.18, n.2, p.441-444, 1967.

WILKINSON, J.M. Silages made from tropical and temperates crops. 1. The ensiling process and its influence on feed value. World Animal Review, v.45, n.45, p.36-42, 1983.

WOOLFORD, M.K. The silage fermentation. New York: Marcel Dekker, 1984. 350p.

Recebido em: 16/02/04

Aceito em: 26/04/05 